\title{
A categoria trabalho nos dizeres de alunos da educação de jovens e adultos de Brasil e Argentina.
}

Hugo Leonardo Prata ${ }^{1}$

\section{Resumo:}

Apresentamos um recorte da pesquisa realizada no âmbito do doutorado em Educação na Universidade Nacional de Córdoba, Argentina. Utilizamos partes de entrevistas realizadas em uma escola no Rio de Janeiro, BR e em Córdoba, AR. Trabalharemos com uma categoria criada e desenvolvida na tese a partir de interlocuções com a bibliografia e a posterior análise. Objetivamos analisar as condições materiais dos sentidos dos discursos de alunos da Educação de Jovens e Adultos de Brasil e Argentina sobre a categoria trabalho. Nos fundamentamos em uma metodologia qualitativa. Tivemos como fulcro teórico a Análise de Discurso. A partir dos Recortes discursivos, observamos uma exaltação do trabalho.

Palavras - chave: Educação. Trabalho. Educação de Jovens e Adultos.

\section{Resumen:}

Presentamos un extracto de la investigación realizada en el ámbito del Doctorado en Educación de la Universidad Nacional de Córdoba. Utilizamos partes de encuestas realizadas en una escuela en Río de Janeiro y Córdoba. Trabajaremos con una categoría creada y desarrollada en la tesis a partir de interlocuciones con la bibliografía y el posterior análisis. Nuestro objetivo es analizar las condiciones materiales de los significados de los discursos de estudiantes de Educación de Jóvenes y Adultos de Brasil y Argentina en la categoría trabajo. Nos basamos en una metodología cualitativa. Tuvimos el análisis del discurso cómo punto de apoyo teórico. De los recortes discursivos, vemos una exaltación del trabajo.

Palabras Claves: Educación. Laburo. Educación de Jóvenes y Adultos.

\section{Introdução}

A vida moderna impõe uma vida dividida em etapas estanques e quase imutáveis; o tempo na contemporaneidade segue um tempo

\footnotetext{
${ }^{1}$ Universidade Federal Fluminense - UFF
} 
linear e previsível: um tempo voltado à formação, e outro para a inclusão no mundo do trabalho. Contribuindo com a discussão relacionada ao tempo, Sánchez Gamboa (1999) menciona a escola de Prigogine, que procura superar os relativismos baseados na compreensão subjetiva de tempo como duração matemática quântica de Borh, ou de tempo sem direção, Einstein. De acordo com o autor, a inclusão do tempo como realidade "cosmológica (ontológica), além das nossas medidas (subjetivas), e a integração do "devir" (tempo irreversível) ao "ser" caracteriza uma nova perspectiva da ciência contemporânea." Trazendo desta forma, valiosas contribuições.

Ressaltamos ainda que, o uso de idades cronológicas tem servido ao modelo que tem no trabalho seu tempo principal, e assim, não só a vida passa a ser segmentada e se impede o acesso à escola daqueles que não tiveram oportunidade no tempo que a ele seria destinado. Segundo Gaullier (1989), este tempo dividido de forma estanque, sugerindo o que cada um deve fazer em determinada etapa da vida, não cabe mais. A vida não segue mais esta linearidade simplista: formação, trabalho e repouso. Os tempos da vida atualmente ganham nova perspectiva mesclando tanto o trabalho com a formação e vice-versa, e, certamente, como resultado das políticas do modelo social vigente, trabalho e não trabalho se misturam também. Com efeito, surge como questão o fato de que manter inseridos no contexto educacional pessoas de diversas gerações não é uma tarefa das mais fáceis de administrar.

Dentro deste contexto de dificultades, Lorenzatti (2005) menciona a categoría "homologación normativa":

(...) de mayor poder explicativo que da cuenta de la existencia de un consentimiento tácito, una aprobación por parte del Estado que la Transformación Educativa en jóvenes y adultos adquiere las mismas características que la Transformación Educativa en general. Se trata de un término que proviene de 
la esfera jurídica y quiere decir consentimiento o aprobación. En otras palabras, implica constreñir la mirada a un sujeto adulto ideal y no a un sujeto social concreto y político. (LORENZATTI, 2005, p.1)

Grande parte dos países inclui a educação como um direito e um dever do Estado em suas respectivas constituições, entretanto, o abandono escolar dos jovens sem que tenham completado a educação básica é uma constante nos países da América do Sul, incluindo Brasil e Argentina. A este fato se incluem variados motivos, que tanto podem passar pela pouca atratividade da escola, tendo como causa e efeito o contínuo fracasso escolar, como também de causas que se justificam nas ilegalidades sociais. Muitos jovens se vêem na necessidade de se inserir bem cedo no mercado de trabalho, seja para auxiliarem a família, seja para o seu próprio sustento.

Programas educacionais especiais são regularmente propostos neste sentido. Assim o sistema educacional abre suas portas para atender tanto jovens em descompasso com as idades previstas nas legislações oficiais, quanto adultos e as pessoas mais velhas que querem adquirir novos conhecimentos e qualificar-se para o contexto social em que estão inseridos. A educação voltada para jovens e adultos, por si só, se constitui como um avanço no sentido de permitir a todos, independentemente da idade cronológica, ter acesso ao ensino básico e fundamental.

A Educação de Jovens e Adultos se configura em um importante campo da área educacional. É um campo de políticas e reflexões que está para além dos limites da escolarização, já que, se ela existe, significa que algo está errado nesse processo de educação/sociedade.

Nesse sentido, Arroyo (2011) vai dizer que a educação de jovens e adultos é um campo de práticas e reflexão que inevitavelmente transborda os limites da escolarização em sentido 
estrito, é antes de tudo, provocar nos sujeitos sua condição de sujeitos autônomos.

No caso da Educação de adultos, a proposta educacional sugerida pelo educador brasileiro Paulo Freire (1989) mostrou-se desafiadora e reconhecida internacionalmente. Ela serve até os dias de hoje como modelo educacional cuja base conceitual contribui aos educadores que veem no processo educacional uma possibilidade de transformar a sociedade.

Por outro lado, Gadotti e Romão (2007) defendem que o conceito de Educação de Adultos vai-se movendo na direção do de Educação Popular, na medida em que a realidade começa a fazer algumas exigências à sensibilidade e à competência científica dos educadores e das educadoras. Uma dessas exigências está relacionada com a compreensão crítica dos educadores do que vem ocorrendo na cotidianidade do meio popular. Segue o autor, explicitando que:

(...) a Educação de Adultos, transformando-se em Educação Popular é, antes de tudo, o processo mais abrangente. Estudiosos educadores descobriram que Educação População é, sobretudo, o processo permanente de refletir a militância, "refletir, portanto, a sua capacidade de mobilizar em direção a objetivos próprios. A prática educativa, reconhecendo-se como prática política, se recusa a deixar-se aprisionar na estreiteza burocrática de procedimentos escolarizantes." (GADOTTI E ROMÃO, 2007, p.16).

A Educação de Jovens e Adultos é uma modalidade de ensino que historicamente foi tratada de forma compensatória nas políticas educacionais. Os resultados dessas políticas resultaram em diversos problemas que ainda não foram resolvidos em pleno século XXI.

A seguir, citamos algumas das principais iniciativas internacionais relacionadas à educação de jovens e adultos: 
A conferência Mundial sobre "Educação para Todos", lançada em Omitem em 1990, enfatiza a educação básica para todos em qualquer espaço e idade. Passados 10 anos sem ter cumprido as metas, o Foro Mundial de Educação (Dakar, abril 2000), 180 países decidiram estender o prazo até o ano de 2015. As metas relacionadas à educação de adultos (metas 3 e 4) têm como objetivo geral permitir o acesso de todos à educação básica e à educação permanente para o ano de 2015 e reduzir o analfabetismo adulto para a metade. As metas estão estruturadas em torno da idade e têm como eixo a educação básica. (...) Metas de Desenvolvimento do Milênio (MDM). Tem a característica de ser multissetorial, sem nenhum foco específico em um setor particular. Ainda que duas das oito metas se refiram especificamente ao setor da educação, nenhuma delas inclui a educação de adultos. Contudo, a aprendizagem e a educação de adultos são transversais a todas as metas e condições para o seu cumprimento. (VALDÉS,2014p.40)

A cada 12 anos aproximadamente, a UNESCO convoca a Conferência Internacional de Educação de Adultos (CONFINTEA), que tem por temática central o diálogo de política e da defesa ativa em matéria de educação de adultos. Trata-se de uma conferência única em seu gênero em nível mundial. A sexta edição do CONFINTEA ocorreu em dezembro de 2009 em Belém do Pará, Brasil, onde estiveram presentes mais de mil participantes provenientes de 150 países, entre eles representantes de organismos internacionais, ONGs e associações de educandos, além de mais de 70 ministros. O Marco da Ação de Belém, resultado desta conferência:

É um documento consolidado e aprovado por 144 países, que contém propostas e recomendações para melhorar a política, a governança, o financiamento, a participação e a qualidade da alfabetização e da educação de adultos, assim como da educação ao longo da vida.(...) METAS 2021.É uma iniciativa da Organização 
dos Estados Ibero-americanos para a Ciência, a Educação e a Cultura (OIE) aprovada em dezembro de 2010. Seu objetivo é alcançar, ao longo da próxima década, uma educação que responda de maneira satisfatória às demandas sociais estabelecidas: conseguir que mais alunos estudem, durante mais tempo, com uma oferta de qualidade reconhecida, equitativa e inclusiva, em que participe a grande maioria das organizações e setores da sociedade. Conta com doze metas gerais que contêm indicadores específicos e metas definidas. A sétima meta geral se refere ao asseguramento a todas as pessoas de oportunidades de educação ao longo da vida, estabelecendo como indicador no primário e no secundário em 2021.

De acordo com De La Fare e Corrêa (2015), no Brasil, a Constituição Nacional de 1988 deu prioridade à escolarização quando constituiu que o dever do Estado com a educação compreende o direito ao ensino fundamental, inclusive para as pessoas que não tiveram acesso na idade própria. Posteriormente, a Lei de Diretrizes Básicas 9.394/96, incorporou uma mudança conceitual ao utilizar o termo Educação de Jovens e Adultos em detrimento do Ensino Supletivo. No ano 2000 foram aprovadas as Diretrizes Curriculares Nacionais para a Educação de Jovens e Adultos.

Segundo as autoras, essas diretrizes contemplam um conjunto de itens: conceito e funções da EJA; bases legais históricas e vigentes; cursos; exames e Plano Nacional de Educação. Essas diretrizes focalizam na EJA escolar e reconhecem para essa modalidade educativa três funções:

Função reparadora, referida ao ingresso no circuito dos direitos civis pela restauração de um direito negado; função equalizadora, como garantia de uma redistribuição e alocação em vista de uma maior igualdade que proporcione mais oportunidades de acesso e permanência na escola e uma função qualificadora, referida às necessidades de atualização e 
aprendizagem contínuas vinculadas à noção de aprendizagem ao longo da vida (DE LA FARE e CORRÊA, 2015, p.348).

Ainda segundo as autoras, na Argentina atual, o ordenamento nacional valorizou a EJA escolar, reconhecida pela lei de educação nacional (LEN) como parte da estrutura do sistema educativo organizado a partir de quatro níveis e oito modalidades educativas. A partir dessa lei, a EJA passou a ser denominada Educação Permanente de Jovens e Adultos (EPJA), modalidade educativa destinada a garantir "a alfabetização e o cumprimento da obrigatoriedade escolar às pessoas que não puderam completar a dita obrigatoriedade nas idades estabelecidas regulamentarmente" e a ofertar educação ao longo da vida.

A LEN estabeleceu onze objetivos para a EJA que incluem critérios de organização curricular e institucional. Citamos alguns:

(...) "Ofertar formação básica para adquirir conhecimentos e desenvolver habilidades de expressão, comunicação, relacionamento interpessoal e construção do conhecimento contemplando as particularidades socioculturais, de trabalho, contextuais e pessoas da população-alvo; honrar a formação profissional e/ou aquisição de uma preparação para o emprego; d) incorporar conteúdos básicos relativos à igualdade de gênero e à diversidade cultural; promover a inclusão do adulto idoso e de pessoas com deficiência, temporária ou permanente; facilitar uma certificação parcial e validação das competências adquiridas através da experiência profissional" (DE LA FARE e CORRÊA, 2015,p.347).

Além do mencionado anteriormente, essa lei também atentou para a necessidade de programas para terminar com 0 analfabetismo, para a conclusão da escolaridade obrigatória, no caso de pessoas maiores de dezoito anos que não puderam completar a escolaridade obrigatória. 
Os sujeitos da EJA/EPJA

Nas palavras de Di Pierro (2008), os parâmetros convencionais para definir os destinatários da EJA/EPJA na América Latina, portanto, Brasil e Argentina, foram concebidos sob a defesa da visão compensatória, restrita à recuperação de estudos formais, motivo pelo qual tomam a educação escolar como referência e combinam um limite mínimo de idade com certo grau de atraso nos níveis de instrução. Continua a autora ao dizer que:

À luz desses critérios, e devido à magnitude do fenômeno no continente, os analfabetos absolutos com 15 anos ou mais foram considerados os sujeitos prioritários da EPJA. A ampliação das exigências sociais de conhecimento, em paralelo ao alargamento do conceito de alfabetização, conduziu por sua vez à inclusão entre os destinatários da EPJA dos jovens e adultos com escolaridade reduzida e de baixa qualidade, que, em virtude da transição demográfica e dos insucessos dos sistemas de ensino, configuram um contingente extremamente numeroso (DI PIERRO, p.372,373).

Ainda segundo Di Pierro, a categoria mais adequada para definir os sujeitos da EJA/EPJA é a da exclusão, porque compreende o conjunto de processos socioeconômicos e culturais que possibilitem aclarar a distribuição desigual do analfabetismo e do atraso escolar nas sociedades, incluindo, sobretudo, a distribuição socioespacial da pobreza.

Por conseguinte, Mészáros (2008, p.65) expõe que o papel da educação é absoluto, tanto para a elaboração de estratégias apropriadas e adequadas para mudar as condições objetivas de reprodução, como para a auto mudança consciente dos indivíduos chamados a concretizar a criação de uma ordem social metabólica radicalmente diferente. 
Apontamos como estratégia a opção por trabalhar nesta investigação com alunos da Educação de Jovens e Adultos (EJA), uma vez que esta é a única modalidade de ensino que nos possibilitou ter acesso a um grupo de estudantes com tamanha variação de idades. Outro ponto de interesse que se faz necessário demarcar está relacionado ao fato de a EJA ser frequentada majoritariamente por trabalhadores. De lã Fare e Corrêa (2015), ao problematizarem sobre a diversidade dos grupos que compõem a EJA, mencionam: as populações itinerantes, do campo, comunidades indígenas e quilombolas, jovens e adultos com deficiência e baixo nível de escolaridade, os idosos e, finalmente, os trabalhadores e aqueles com potencial para o mercado de trabalho.

Parâmetros metodológicos

Acreditamos que a opção por um método analogamente implicará escolhas, que, de maneira inevitável, terá como referencial a visão de mundo do pesquisador. Neste sentido, buscamos nos fundamentar na perspectiva do materialismo histórico dialético. Formulado por Karl Marx e Friedrich Engels, como caracterização, o termo materialismo corresponde à condição material da existência humana. O termo histórico parte da percepção de que a compreensão da existência humana implica a assimilação de seus condicionantes históricos, e o termo dialético tem como pressuposição o movimento da contradição produzida na própria história.

Frigotto (1989, p. 23) faz uma demarcação em relação a esta concepção. É explicitado que, todavia, como uma posição, ou compreensão de mundo, "enquanto um método que permite uma apreensão radical (que vai à raiz) da realidade e enquanto práxis, isto é, unidade de teoria e prática na busca da transformação e de 
novas sínteses no plano do conhecimento e no plano da realidade histórica."

Em relação ao método, para Netto (2011), fazendo referência a Marx,

Numa palavra: o método de pesquisa que propicia 0 conhecimento teórico, partindo da aparência, visa alcançar a essência do objeto. Alcançando a essência do objeto, isto é: capturando a sua estrutura e dinâmica, por meio de procedimentos analíticos e operando a sua síntese, o pesquisador a reproduz no plano do pensamento; mediante a pesquisa, viabilizada pelo método, o pesquisador reproduz, no plano ideal, a essência do objeto que investigou. (...) 0 conhecimento teórico é o conhecimento do objeto tal como ele é em si mesmo, na sua existência real e efetiva. (...) A teoria é, para Marx, a reprodução ideal do movimento real do objeto pelo sujeito que pesquisa: pela teoria, o sujeito reproduz em seu pensamento a estrutura e a dinâmica do objeto que pesquisa. (NETTO, p.16,17)

Como bem observa Sánchez Gamboa (2012), os métodos dentro de um contexto menos técnico e mais epistemológico se referem aos diversos modos como se constrói a realidade, às diferentes maneiras como nos aproximamos do objeto do conhecimento. Isto quer dizer que a questão do método exige análises mais complexas e não se reduz apenas à parte instrumental da pesquisa.

Em relação à dialética, sob 0 enfoque do materialismo histórico, parte do conceito basilar de que o mundo não pode ser classificado como um complexo de coisas acabadas, mas, sim, um processo de complexos, Mészáros (2011), no que the concerne, expõe que a abordagem dialética tem a precaução de trazer à tona as conexões objetivas internas de um complexo, enquanto traça as linhas necessárias de demarcação, definindo os limites. "Nas 
palavras de Marx - entre as multiplicidades dos "momentos" constitutivos que configuram a estrutura geral."

Por conseguinte, segue Mészáros (2011): o objeto de uma investigação dialética deve ser apreendido como uma totalidade, cujas partes não estão meramente interconectadas, nem são igualmente importantes, mas constituem um todo estruturado, com sua ordem interna apropriada e hierarquias determinadas, ainda que estas devam ser entendidas como dinamicamente em mudança e transformação, em consonância com a natureza inerente de um complexo dialético.

Sánchez Gamboa (2012), por sua vez, reconhece a existência de muitos tipos de dialética, no entanto, de acordo com as suas palavras, a dialética é entendida como método que nos permite conhecer a realidade concreta no seu dinamismo e nas interrelações. O autor prossegue, referindo-se a Marx, em o método da Economia Política (1983), onde é apresentada a dialética como o processo de construção do concreto do pensamento a partir do concreto real.

O que se denomina concreto não é mais do que a síntese de múltiplas determinações mais simples, é o resultado, no pensamento, de numerosos elementos cada vez mais abstratos que vão ascendendo até construir o concreto. O concreto é concreto porque é a síntese, e a unidade do diverso é o resultado e não o ponto de partida. Para uma maior compreensão da dialética, é importante distinguir o concreto real, que é o objeto real que se deve conhecer, e o concreto do pensamento, que é o conhecimento daquele objeto real. (GAMBOA, 2012, p.38).

Dando prosseguimento, mencionamos, que tendo como fulcro teórico a Análise de Discurso, que, de acordo com Pêcheux e Fuchs (1997), está imbricada com a articulação de três regiões do conhecimento: o materialismo histórico, a linguística e o discurso. Propomo-nos a analisar as condições materiais dos sentidos dos 
discursos de alunos da Educação de Jovens e Adultos de Brasil e Argentina sobre a categoria trabalho.

Pêcheux e Fuchs (1997), no texto titulado "A propósito da Análise Automática do discurso: atualização e perspectivas", apresentam o quadro teórico da $A D$, com a articulação das três regiões do conhecimento:

O materialismo histórico, como teoria das formações sociais e de suas transformações, compreendida aí a teoria das ideologias; 2. a linguística, como teoria dos mecanismos sintáticos e dos processos de enunciação ao mesmo tempo; 3. a teoria do discurso, como teoria da determinação histórica dos processos semânticos. Convém explicitar ainda que estas três regiões são, de certo modo, atravessadas e articuladas por uma teoria da subjetividade de natureza psicanalítica (PÊCHEUX e FUCHS, 1997, p.163,164)

Em se tratando deste quadro teórico, Magalhães e Sobrinho (2013) fazem algumas considerações. Os autores expõem que, na Análise de Discurso, o Materialismo Histórico é necessário para a compreensão das formações sociais, seu movimento dialético de transformação e a ideologia em seu funcionamento. Este lugar do Materialismo Histórico na $A D$ não dispensa a efetiva consideração das condições de produção. Estas são as relações de produção/reprodução/transformação das relações sociais que, numa sociedade regida pelo Capital, toma caráter de relações de exploração do trabalho na produção-consumo de mercadorias, manifestadas em interesses e conflitos de classes.

Segundo Orlandi (2012), com os três domínios disciplinares: a Linguística, o Marxismo e a Psicanálise, a Análise de Discurso se estabelece no espaço de questões criadas por esta relação, que são ao mesmo tempo uma ruptura com o século XIX.

Dentro deste contexto, para Análise de Discurso: 
A Linguística constitui-se pela afirmação da não transparência da linguagem: ela tem seu objeto próprio, a língua, e esta tem sua ordem própria. Esta afirmação é fundamental para a Análise de Discurso, que procura mostrar que a relação linguagem/ pensamento/ mundo não é unívoca, não é uma relação direta que se faz termo-a-termo, isto é, não se passa diretamente de um a outro. Cada um tem sua especificidade. Por outro lado, a Análise de Discurso pressupõe o legado do materialismo histórico, isto é, o de que há um real da história de tal forma que o homem faz história, mas esta também não lhe é transparente. Daí, conjugando a língua com a história na produção de sentidos, esses estudos do discurso trabalham o que vai se chamar a forma material (não abstrata como a da Linguística), que é a forma encarnada na história para produzir sentidos: esta forma é, portanto, linguístico-histórica (ORLANDI, 2012, p. 19)

Seguindo com Orlandi (2012), é explicitado que, nos estudos discursivos, não são separados forma e conteúdo e que se busca a compreensão da língua não apenas como uma estrutura, mas, sobretudo, como acontecimento. Desta maneira se reúnem estrutura e acontecimento, "a forma material é vista como o acontecimento do significante (língua) em um sujeito afetado pela história”. Nesta perspectiva entra a contribuição da Psicanálise, com o deslocamento da noção de homem para a de sujeito. Este, por sua vez, se estabelece na relação com o simbólico, na história.

De tal modo, para a Análise de Discurso:

A língua tem sua ordem própria, mas só é relativamente autônoma (distinguindo-se da Linguística, ela reintroduz a noção de sujeito e de situação na análise da linguagem); a história tem seu real afetado pelo simbólico (os fatos reclamam sentidos); o sujeito de linguagem é descentrado, pois é afetado pelo real da língua e também pelo real da história, não tendo o controle sobre o modo como elas o afetam. Isso redunda em 
dizer que o sujeito discursivo funciona pelo inconsciente e pela ideologia. (ORLANDI 2012, p. 19)

"As palavras simples do nosso cotidiano já chegam até nós carregadas de sentidos que não sabemos como se constituíram e que, no entanto, significam em nós e para nós". (ORLANDI, 2012, p.20)

Dentro desta perspectiva, como citado anteriormente, para Orlandi a Análise de Discurso como herdeira das três regiões de conhecimento: a Psicanálise, a Linguística e o Marxismo, não o faz de maneira servil e trabalha uma perspectiva, a de discurso, que não é reduzido ao objeto da Linguística, não permite uma absorção irrefletida da Teoria Marxista e não corresponde ao que teoriza a Psicanálise. A Linguística é interrogada pela historicidade que ela deixa de lado, é questionado o Materialismo indagando pelo simbólico, e difere da Psicanálise pela maneira como, considerando a historicidade, trabalha a ideologia como materialmente relacionada ao inconsciente sem ser absorvida por ele.

Nas palavras da autora, os elementos de sujeito e de linguagem encontrados na base das ciências Humanas e Sociais no século XIX se encontram desatualizados posteriormente à contribuição da linguística e da Psicanálise. De outra forma, tampouco a compreensão de Língua (como sistema abstrato) pode ser observada da mesma maneira com a contribuição do materialismo.

Seguindo com Orlandi (2012), é explicitado que se faz necessário reconhecer que uma ciência, na realidade, já traz na sua própria constituição os rumos e os riscos a que se expõe, não sendo diferente com a análise de discurso: as direções e os riscos "estão no fato de que se caracteriza como uma teoria de entremeio; ela aí se constitui não como outra alternativa, mas trabalhando as suas contradições, pensadas em suas relações" 
A análise de discurso, trabalhando na confluência desses campos de conhecimento, rompe em suas fronteiras produzindo um novo recorte de disciplinas, formando um novo objeto que afetará essas formas de conhecimento em seu conjunto: este novo objeto é o discurso.

Trabalho

Ergueu no patamar quatro paredes mágicas

Tijolo com tijolo num desenho lógico

Seus olhos embotados de cimento e tráfego

Sentou pra descansar como se fosse um príncipe

Comeu feijão com arroz como se fosse o máximo

(...) por esse pão pra comer, por esse chão pra dormir

A certidão pra nascer e a concessão pra sorrir

Por me deixar respirar, por me deixar existir

Deus lhe pague.

(Música Construção, Chico Buarque)

Iniciamos estas reflexões com as palavras de Antunes (2000): "Por errar, Adão trabalhou. Por trabalhar, Prometeu errou".

Aranha e Martins (1993), ao tratar o tema do trabalho, expõem que a sua compreensão predominantemente esteve ligada a uma visão negativa. Na Bíblia, Adão e Eva vivem felizes até que o pecado provoca sua expulsão do Paraíso e a condenação ao trabalho com o "suor do seu rosto". A Eva coube também o "trabalho" do parto. A etimologia da palavra trabalho vem do vocábulo latino tripaliare, do substantivo tripalium, aparelho de tortura formado por três paus, ao qual eram atados os condenados e que também servia para manter presos os animais difíceis de ferrar. Daí a associação do trabalho com tortura, sofrimento, pena, labuta.

$\mathrm{Na}$ Grécia antiga, todo trabalho manual é desvalorizado por ser realizado por escravos, enquanto as atividades tidas como 
intelectualizadas estavam entre as mais dignas realizadas pelo homem. "Representa a essência fundamental de todo ser racional. Para Platão, por exemplo, a finalidade dos homens livres é justamente a contemplação das ideias". (ARANHA e MARTINS, 1993, p. 46). As autoras seguem tratando o tema, citando a Roma escravagista, onde também o trabalho era desvalorizado. Na Idade Média, Tomás de Aquino busca uma reabilitação para o trabalho manual, proferindo que existe uma equivalência entre todos os trabalhos. Para as autoras, no entanto, a própria construção teórica de seu pensamento, baseada na visão grega, tende a valorizar a atividade contemplativa. Um exemplo ilustrativo está colocado na constatação de que diversos textos medievais consideravam a arte mecânica uma arte inferior.

$\mathrm{Na}$ Antiguidade, distinguia-se trabalho de labor. Estas palavras apresentam etimologia distinta para indicar o que na atualidade é considerado como a mesma atividade. Ambas guardam seu sentido, a despeito de serem frequentemente utilizadas como sinônimos. "O labor é a atividade que corresponde ao processo biológico do corpo humano. $O$ trabalho é a atividade correspondente ao artificialismo da existência humana. A ação corresponde à condição humana" (ALBORNOZ, 1988, p. 23).

$\mathrm{Na}$ Idade Moderna, em função da conjuntura existente naquele momento, para Aranha e Martins (1993), é o início de uma alteração de uma dada concepção de trabalho. $O$ crescente interesse pelas artes mecânicas e pelo trabalho em geral justifica-se pela ascensão dos burgueses, oriundos de segmentos dos antigos servos que compravam sua liberdade e dedicavam-se ao comércio, e que, portanto, tinham outra concepção a respeito do trabalho.

Dentro deste contexto, estamos de acordo com o exposto por Marx e Engels (2006), no que diz respeito à afirmação de que aquilo que os homens são condiz com a sua produção, "com o que produzem e também com o como produzem. Aquilo que os 
indivíduos são, depende, portanto, das condições materiais da sua produção". A pressuposição é o da centralidade da análise do modo de produção, para que seja possibilitada a compreensão do homem e das relações sociais constituídas coletivamente, já que são essas formas de reprodução que intervêm nos direcionamentos dados aos determinantes da vida social.

Seguindo com os autores, Marx e Engels, é explicitado que, para o homem ser "considerado" homem, o trabalho é a condição primeira, pois é algo que o diferencia do animal, haja vista que não existe a possibilidade de compreensão das relações que constitui em sua vida, sem perpassar a forma de reproduzir materialmente sua própria existência. Portanto, a configuração de reprodução das condições materiais da sociedade, onde 0 trabalho constitui-se central, é fator determinante das construções sociais.

Segundo Saviani (1994), o ato de agir sobre a natureza, adaptando-a às necessidades humanas, é o que conhecemos pelo nome de trabalho. Por isso, podemos dizer que o trabalho define a essência humana. Logo, o homem, para continuar existindo, precisa estar continuamente produzindo sua própria existência através do trabalho. Isto faz com que a vida do homem seja determinada pelo modo como ele produz sua existência.

Sousa Junior (2010), ao abordar a temática do trabalho, baseada também nos autores citados anteriormente, argumenta que existem dois planos de análise nos quais se colocam especificidades para a reflexão sobre o trabalho em Marx. O primeiro plano está relacionado à atividade que representa a condição fundamental da existência humana, como citamos anteriormente. Noutro plano de análise, quando o trabalho é considerado segundo as condições históricas determinadas, quando ele é analisado como atividade realizada concretamente sob as condições dadas da sociedade do capital, como "trabalho abstrato, trabalho alienado, trabalho assalariado, ele passa a ser central de uma forma particular de 
sociedade, da ordem do capital".. O autor segue argumentando que, sem deixar de ser atividade vital para a condição da existência humana em geral, o trabalho adquire determinidades históricas concretas que se opõem à qualidade destacada no primeiro plano.

Dentro desta perspectiva, além de ser atividade vital da humanidade, o trabalho passa a ser também o pilar fundamental da sociedade negadora do homem. Nesse plano de análise, diferentemente do anterior e em oposição a ele, o trabalho adquire uma negativa muito intensa. Deste modo, existe uma significativa distinção em meio à forma de determinar a centralidade do trabalho como atividade vital da humanidade "e o modo como se define a centralidade do trabalho quando este é a sustentação da sociedade do capital, quando é o sustentáculo da ordem social alienada, fetichizada e estranhada do capital."

Nas palavras de Taffarel, Lacks e Santos Júnior (2011), o trabalho é uma condição da existência humana que independe de qual seja a forma de sociedade. O processo de trabalho é uma condição da existência humana, é comum a todas as formas de sociedade, mas se diferencia pelas relações sociais estabelecidas. É uma necessidade que atua como mediador entre o homem e a natureza, logo, o da própria vida humana.

Dentro deste contexto, Antunes (2002) fala da história da realização do ser social,

"Objetiva-se através da produção e reprodução da sua existência, ato social que se efetiva pelo trabalho. Este, por sua vez, desenvolve-se pelos laços de cooperação social existentes no processo de produção material". Dito de outra forma, o ato de produção e reprodução da vida humana realiza-se pelo trabalho. É a partir do trabalho, em sua cotidianidade, que o homem se torna ser social, distinguindo-se de todas as formas não humanas. Para o autor, uma ocorrência determinante é que o ser humano conceba, 
em sua consciência, a configuração que quer imprimir ao objeto do trabalho, antes de sua realização.

Seguindo com Antunes (2002), é explicitado que, no trabalho, o momento assinalado, fundamentalmente, é constituído pela manifestação do ato consciente, que, no ser social, abandona a condição de ser um mero produto acidental da reprodução biológica. "O trabalho é um ato de pôr consciente e, portanto, pressupõe um conhecimento concreto, ainda que jamais perfeito, de determinadas finalidades e de determinados meios". Desta maneira, para o autor, remete-se a uma dimensão basilar da subjetividade do ser, à dimensão teleológica.

O trabalho apresenta-se como momento fundante de concretização do ser social, "condição para sua existência; é o ponto de partida para a humanização do ser social e o motor decisivo do processo de humanização do homem.". Antunes (2002), fundamentando-se em Marx, profere que o significado dado pelo autor ao enfatizar que, como criador de valores de uso, como trabalho útil, é o trabalho, por isso, uma condição de existência do homem, independentemente de todas as formas de sociedade, eterna necessidade natural de mediação do metabolismo entre homem e natureza e, portanto, vida humana. Permite compreender o trabalho como a única lei objetiva e ultra universal do ser social, que é tão "eterna" quanto o próprio ser social; ou seja, trata-se também de uma lei histórica, na medida em que nasce simultaneamente com o ser social, mas que permanece ativa apenas enquanto este existir.

Antunes (2002), ao utilizar mais uma vez um dos autores clássicos no domínio da temática do trabalho, cita Lukács:

Por um lado, o próprio homem que trabalha é transformado pelo seu trabalho; ele atua sobre a natureza; "desenvolve as potências nela ocultas" e subordina as forças da natureza "ao seu próprio poder". Por outro lado, os objetos e as forças, da natureza são transformados em meios, em objetos de trabalho, 
em matérias-primas etc. $\mathrm{O}$ homem que trabalha "utiliza as propriedades mecânicas, físicas e químicas das coisas, a fim de fazê-las atuar como meios para poder exercer seu poder sobre outras coisas, de acordo com sua finalidade". (ANTUNES, 2002, p.124)

Seguindo com Antunes (2002), é explicitado que, apesar de a formulação Marxiana colocar que o trabalho é o ponto de partida do processo de humanização do ser social, é fato que, tal como se objetiva na sociedade capitalista, o trabalho é degradado e aviltado, torna-se estranhado. Antunes faz uma diferenciação entre estranhamento e alienação, optando pela primeira, como veremos a seguir:

Utilizamos a expressão trabalho estranhado e não alienação porque, enquanto esta última é um aspecto ineliminável de toda objetivação, o estranhamento refere-se à existência de barreiras sociais que se opõem ao desenvolvimento da personalidade humana. Como disse Lukács: Somente quando as formas objetificadas da sociedade adquirem ou assumem funções que põem a essência do homem em contraposição à sua existência, submetem a essência humana ao ser social, a deformam ou dilaceram. Em outras palavras, o desenvolvimento das forças produtivas acarreta necessariamente o desenvolvimento da capacidade humana, mas - e aqui emerge plasticamente o problema do estranhamento - o desenvolvimento da capacidade humana não produz necessariamente 0 desenvolvimento da personalidade humana, mas, ao contrário, pode desfigurá-la e aviltá-la. (ANTUNES, 2002

Neste sentido, o que seria necessário constituir-se na finalidade básica do ser social, a sua realização no trabalho e pelo trabalho, "é pervertido e depauperado. O processo de trabalho se converte em meio de subsistência. A força de trabalho torna-se, 
como tudo, uma mercadoria, cuja finalidade vem a ser a produção de mercadorias".

Ante o exposto, continuamos com as reflexões de Antunes (2002), que argumenta que o que careceria ser a forma humana de realização do indivíduo abrevia-se à única possibilidade de subsistência para aqueles que são obrigados a vender sua força de trabalho. "A precariedade e perversidade do trabalho na sociedade capitalista, onde 0 trabalho torna-se meio e não "primeira necessidade" de realização humana, o trabalhador decai a uma mercadoria e à mais miserável mercadoria".

Contribuindo com o exposto, mencionamos o livro: A poesia de Brecht e a história, de 1996 de autoria de Leandro Konder. "Para Brecht, uma coisa era certa: os de "baixo" - com os quais ele se solidarizava -precisavam se unir contra os de "cima". A força dos privilegiados, a rigor, era mais provisória que a capacidade de resistência dos oprimidos". Entre os diversos temas tratados por Brecht, o trabalhador teve papel de destaque como podemos observar no poema intitulado: Perguntas de um trabalhador que lê.

Quem construiu Tebas, a cidade das sete portas?

Nos livros estão nomes de reis; os reis carregaram pedras?

E Babilônia, tantas vezes destruída, quem a reconstruía sempre?

Em que casas da dourada Lima viviam aqueles que a

Edificaram?

No dia em que a Muralha da China ficou pronta,

Para onde foram os pedreiros?

A grande Roma está cheia de arcos-do-triunfo:

Quem os erigiu? Quem eram

Aqueles que foram vencidos pelos césares? Bizâncio, tão

Famosa, tinha somente palácios para seus moradores? Na

Legendária Atlântida, quando o mar a engoliu, os afogados

Continuaram a dar ordens a seus escravos. 
O jovem Alexandre conquistou a Índia.

Sozinho?

César ocupou a Gália.

Não estava com ele nem mesmo um cozinheiro? Felipe da

Espanha chorou quando sua frota

Naufragou. Foi o único a chorar?

Frederico Segundo venceu a guerra dos sete anos. Quem

Partilhou da vitória?

A cada página uma vitória.

Quem preparava os banquetes comemorativos? A cada dez anos

Um grande homem.

Quem pagava as despesas?

Tantas informações.

Tantas questões.

Interpretação

Análise de Discurso tem como um dos seus objetivos a compreensão de como os objetos simbólicos produzem sentidos, analisando, portanto, os próprios gestos de interpretação que são considerados como atos no domínio simbólico, pois eles intervêm no real do sentido.

A Análise de Discurso não se detém na interpretação. "Trabalha seus limites, seus mecanismos, como parte dos processos de significação. Também não procura um sentido verdadeiro através de uma "chave" de interpretação" (ORLANDI, 2012, p. 26). Não existe esta chave; existe método, existe a construção de um dispositivo teórico. "Não há uma verdade oculta atrás do texto. Há gestos de interpretação que o constituem e que o analista, com seu dispositivo, deve ser capaz de compreender". 
Dentro deste contexto da interpretação, é exposto por Orlandi (2012a) a necessidade de apontar para dois modos de intervenção da noção de interpretação quando se trata do estudo do discurso. É necessário levar em consideração a interpretação no nível do analista, que consiste em interrogar a interpretação e trabalhar sobre ela. A outra forma é a interpretação no nível do próprio objeto da análise; neste sentido, a interpretação faz parte da própria constituição do discurso, do sujeito que diz.

Uma vez que, continua a autora:

(...) A análise de discurso teoriza a interpretação na medida em que ela põe a questão da interpretação, ou melhor, ela põe em questão a interpretação. Se, de um lado, não podemos não interpretar, pois, diante de um objeto simbólico, o sujeito sofre a injunção à interpretação, de outro, a linguagem aparece como transparente como se os sentidos estivessem já sempre lá. (ORALNDI, 2012a, p.170)

Por conseguinte, Orlandi (2012a) expõe que desta maneira temos a interpretação no nível do analista sendo trabalhada por um dispositivo teórico, que permite que o analista leve em conta e não atravesse simplesmente a materialidade do discurso. Nesse sentido esse dispositivo tem a intenção de realizar um deslocamento do olhar leitor do atravessamento pela ideologia "(em que os sentidos aparecem como já - lá na transparência da linguagem) para a posição do analista: não onipotente, mas deslocada", onde o efeito da exterioridade, da alteridade do sentido e sua determinação histórica sejam levados em consideração.

Ao nos reportarmos ao dispositivo teórico da interpretação, baseados na autora, observamos a necessidade de elucidar que existe uma parte que está a cargo do analista e uma parte que decorre da sua sustentação no rigor do método e no alcance teórico da Análise de Discurso. O que é de sua responsabilidade é a 
formulação da questão que desencadeia a análise. Neste sentido, cada material de análise determina que seu analista, de acordo com a questão formulada, mobilize conceitos que outro analista não mobilizaria, diante das suas (outras) questões. Uma análise sempre será diferente da outra, porque mobiliza conceitos díspares, e isso terá resultados cruciais na descrição dos materiais. Um mesmo analista, além do mais, formulando uma questão distinta, também poderia mobilizar conceitos diversos, fazendo distintos recortes conceituais.

É de fundamental importância adicionar que, segundo Orlandi (2012), como a pergunta está a cargo do pesquisador, é essa responsabilidade que situa sua relação com o discurso, levando-o à construção de "seu" dispositivo analítico, elegendo a mobilização de determinados conceitos em detrimento de outros, determinados procedimentos em detrimento de outros, com os quais ele se compromete na resolução de sua questão. Logo, sua prática de leitura, seu trabalho com a interpretação, tem o desenho de seu dispositivo analítico.

Seguindo com a autora, ela se refere ao sentido de que:

Desfeita a ilusão da transparência da linguagem, e exposto à materialidade do processo de significação e da constituição do sujeito, o analista retorna sobre sua questão inicial. Ela está assim no início, como elemento desencadeador da análise e da construção do dispositivo analítico correspondente, e, no final, ela retorna, gerindo a maneira como o analista deve referir os resultados da análise à compreensão teórica do seu domínio disciplinar específico: o da própria Análise de Discurso, se for o caso, ou da Linguística, mas também o da Política, da Sociologia, da Antropologia, etc, dependendo da disciplina a que se filia o analista. (ORLANDI, 2012, p. 28) 
Diante do exposto, dentre estes diversos elementos, o caráter dos materiais analisados, a questão colocada, as distintas teorias dos diferentes campos disciplinares, tudo isto forma o dispositivo analítico construído pelo analista. Por conseguinte, Orlandi (1996) coloca que, disso, resulta a riqueza da Análise de Discurso ao permitir explorar de muitas maneiras essa relação trabalhada com o simbólico, sem apagar as diferenças, significando-as teoricamente, no jogo que se estabelece na distinção entre o dispositivo teórico da interpretação e os dispositivos analíticos que lhe correspondem.

Considerando que o corpus resulta "de uma construção do próprio analista" (ORLANDI, 2012, p. 63), sua seleção e sua organização constituem, de certa forma, a primeira etapa da análise. Nessa perspectiva, a etapa subsequente do trabalho com o corpus diz respeito ao recorte dos enunciados que constituirão as unidades de análise. Cada recorte constituirá um conjunto de enunciados que serão analisados conforme o dispositivo teórico-analítico da Semântica do Acontecimento, descrita como "uma semântica que considera que a análise do sentido da linguagem deve localizar-se no estudo da enunciação, do acontecimento do dizer" (GUIMARÃES, 2002, p. 7).

Recortes discursivos (R D)

"Como eu falei antes, conforme vai passando a idade as coisas vão ficando mais difíceis, os idosos não tentam muito também, acho que ficam meio acomodados, não querem trabalhar mais, e se não trabalham a vida não faz muito sentido."

"Eu acho que o jovem sempre vai trabalhar melhor. Porque é jovem né! O velho, pode falar velho? Ele é muito desinteressado não quer fazer as coisas. Acho que é porque já trabalhou. Depois não serve muito". 
"muitos nos seus afazeres trabalham bem. É, os jovens teriam a vantagem da força, então, e os, os mais idosos teriam a experiência né no trabalho."

"Tem muitos idosos que tem habilidades como os jovens sim. Tem muita eficiência no trabalho."

"El trabajo es lo que existe de más importante en la vida de las personas, es fundamental, es la vida. No quiero dejar de trabajar nunca. El éxito está vinculado con la cantidad que usted trabaja, eso es seguro. "

"Pero si son personas que estuvieron trabajando toda su vida, que estuvieron activos todo el tiempo me parece que no".

"Si usted no tiene trabajo usted no es nadie, por eso que es importante estudiar, para conseguir un buen trabajo, ser feliz y seguir la vida, si usted no trabaja, no podrá ser feliz.

Nos Recortes Discursivos anteriores, observamos uma exaltação do trabalho. Para problematizarmos os referidos recortes, trazemos as reflexões de Maya (2008). É argumentado que nas sociedades capitalistas, onde o pensamento liberal é hegemônico, o trabalho tem sido exaltado de maneira sistemática. Explicitamos que é comum encontrarmos no cotidiano, formações discursivas do tipo: o trabalho enobrece o homem, ricos são os que trabalharam mais, Deus ajuda a quem cedo madruga para trabalhar. De acordo com esta maneira de pensar, todos os esforços e interesses dos indivíduos devem se voltar para o trabalho. Nesta perspectiva, o processo de socialização no capitalismo é altamente eficaz, já que prepara efetivamente o trabalhador para essa realidade. "A exaltação do trabalho feita pelo discurso ideológico dominante funciona como contrapartida da desvalorização do trabalhador". (MAYA, 2008, p.32).

$\mathrm{Na}$ medida em que a maioria dos membros da sociedade é obrigada a vender a sua força de trabalho, é bastante útil para aqueles que compram essa força de trabalho a ideia de que o 
homem digno é aquele que trabalha e que aqueles que assim não procedem estão destinados ao fracasso.

Sendo assim, para Mészáros (2011), o trabalhador somente poderá ter acesso a uma determinada classe e quantidade de valores de uso, correspondendo ela ou não às suas necessidades reais, enquanto o capital, com base na unidade reconstituída de necessidade (troca) e produção (reprodução), os corrobora como viáveis e lucrativos no interior da estrutura da homogeneização corrente. Desta forma o trabalhador internaliza as necessidades e os imperativos do capital como se fossem seus, como inseparáveis da relação de troca, e por isso aceita a determinação dos valores de uso capitalisticamente viáveis como se decorressem de suas próprias necessidades.

De forma ainda mais perversa, concomitantemente o trabalhador também se acorrenta à sorte do sistema produtivo dominante pela internalização do que ele aceita serem suas próprias necessidades "legítimas". Igualmente que, no devido tempo, "sob as condições do "capitalismo de consumidores" internalizado, o trabalhador, se ousar desafiar a ordem estabelecida, tem de fato muito mais a perder que seus "grilhões externos". (MESZÁROS, 2011, p.628)

Seguindo com o autor, é especificado que o que determina a questão é a relação capital, na qual o controlador do trabalhador deve ser, sob a forma capitalista do domínio do capital, o capitalista e não um capitalista particular ou individual. Este, sendo subsidiário ao conceito de capital em si, enfrenta e domina o trabalhador. Para Mészáros (2011), em todas as formas concebíveis da relação-capital desenvolvida, as condições necessárias são:

A separação e a alienação das condições objetivas do processo de trabalho do próprio trabalho; (2) a imposição de tais condições objetivadas e alienadas sobre os trabalhadores como um poder separado que exerce comando sobre o 
trabalho; (3) a personificação do capital como "valor egoísta" com sua subjetividade usurpada e sua pseudopersonalidade que persegue sua própria auto expansão, com uma vontade própria (sem a qual não poderia ser "capital-para-si" como controlador do sócio- metabolismo); (4) a equivalente personificação do trabalho (isto é, a personificação dos trabalhadores como "trabalho" destinado a entrar numa relação de dependência ou contratual/econômica ou politicamente regulada com o tipo historicamente prevalecente de capital), confinando a identidade do sujeito deste "trabalho" às suas funções produtivas fragmentárias. (MÉSZÁROS (2011, p. 720).

Seguindo com Mészáros (2011), o autor coloca que estas quatro condições básicas são: distintivas do "sistema orgânico" do capital e compatível com todos os tipos de transformações parciais, sem que isso altere sua substância. O capital pode, deste modo, modificar prontamente a configuração do seu domínio enquanto estas quatro condições básicas não forem radicalmente superadas pela formação de um sistema orgânico alternativo.

Por conseguinte, Oliveira (2011) fala da alienação do trabalho; a autora argumenta que, ao considerarmos a temática trabalho, deparamo-nos com um contrassenso, pois, ao mesmo tempo em que o trabalho constrói o homem, ele também o destrói. O debate sobre a alienação tem relação direta com o conceito de trabalho, que apresenta suas bases nas mediações dialéticas entre a sua realização e as transformações no jeito de viver e trabalhar dos coletivos sociais. Nunca é demais relembrarmos que, como trabalhador "livre", o homem vende a sua força de trabalho como mercadoria que o capitalista compra em troca de um salário. Essa relação de troca, apesar de conjecturar uma relação contratual, onde existe um dominante e um dominado, aliena a sua força de trabalho e o seu ser como sujeito.

Acreditamos que a definição de Sanchez Vasquez (1986) em relação ao trabalho seja valiosa; o autor utiliza o termo práxis com o 
mesmo sentido que um grande número de autores utiliza para a palavra trabalho: Por isso, inclinamo-nos pelo termo "práxis" para designar a atividade humana que produz objetos, sem que por outro lado esta atividade seja concebida com o caráter estritamente utilitário, que se infere do "prático" na linguagem comum (SANCHEZ VASQUEZ, 1986, p. 5).

Esta definição amplia a anterior, tornando clara a inclusão na categoria trabalho daquelas atividades que, embora não produzam um objeto concreto, implicam um determinado objetivo a ser alcançado ou algo a ser realizado (o trabalho intelectual, por exemplo, que nem sempre produz um objeto).

Utilizamos as palavras de Oliveira (2011). A autora cita que o caráter contraditório do trabalho é, simultaneamente, afirmaçãonegação, criação-destruição, libertação-servidão, marcada pela expropriação da força de trabalho, acúmulo de riquezas, um processo de alienação cada vez mais perverso e destrutivo do valor humano. Diante desta complexidade, é fundamental destacarmos um outro elemento, que expressa, de um lado, a naturalização do ordenamento capitalista e das desigualdades sociais como inevitáveis. De outro, um retrocesso no dilatamento ideológico da responsabilidade individual como a possibilidade de mudança da realidade do coletivo, na qual pressupõe que a verdadeira mudança está no interior ou no comportamento do indivíduo.

Dentro da complexidade que envolve esta temática, utilizamos uma vez mais as palavras de Antunes (2002):

$\mathrm{Na}$ concretude do capitalismo tem-se, portanto, que "tudo é reificado e as relações ontológicas fundamentais são postas de cabeça para baixo. O indivíduo é confrontado com meros objetos (coisas, mercadorias), quando seu "corpo inorgânico" "natureza trabalhada" e capacidade produtiva externalizada foi dele alienado. Não tem consciência de um "ser pertencente a uma espécie"..., em outras palavras, um ser cuja essência 
não coincide diretamente com a sua individualidade". (ANTUNES, 2002, p.127)

Continua o autor:

Ao invés do trabalho como atividade vital, momento de identidade entre o indivíduo e o ser genérico, tem-se, na sociedade regida pelo capital uma forma de objetivação do trabalho, onde as relações sociais estabelecidas entre os produtores assumem, conforme disse Marx, a forma de relação entre os produtos do trabalho. A relação social estabelecida entre os homens adquire a forma de uma relação entre coisas. (ANTUNES, 2002, p.128).

\section{Considerações finais}

Explicitamos neste momento, que os homens vivem, têm experiências concretas e partindo dessas condições concretas, eles concebem seu imaginário, consequentemente elaboram suas representações e discursos. Ademais, de acordo com Amaral (2018) a produção da vida material constrói vínculos necessários à reprodução social, implicando o arranjo social entre os homens e, por consequência, a consciência de que vive em sociedade. Com efeito, "decorrem as formas de consciência (religiosa, moral etc.) que fazem emergir as formações ideológicas que ganham concretude no discurso - discurso religioso, discurso moral ou ético, discurso político, discurso trabalho e muitos outros".

Dentro deste contexto, baseados em (ORLANDI, 2012) podemos dizer que o discurso se funda em seus "sentidos", pois aquilo que o sujeito diz se registra em uma formação discursiva e não em outra para ter um sentido e não outro. Desta maneira é possível ter uma percepção de que as palavras não têm um sentido nelas próprias. Assim sendo, elas derivam seus sentidos das formações discursivas em que se inscrevem. As formações 
discursivas, por sua vez, representam no discurso as formações ideológicas. Desse modo, os sentidos sempre são determinados ideologicamente.

A formação ideológica que transfere e suscita as ideias dominantes da classe dominante, faz prevalecer a positividade do trabalho. No entanto, "Por sua natureza, também contraditória, permite fazer circular os efeitos de positividade e de negatividade do trabalho. (AMARAL,2018, p.8). Em relação a análise que realizamos a partir dos recortes discursivos, observamos uma materialização do discurso do trabalho como algo positivo.

Concomitantemente, Mészáros (2014), expõe que, nas sociedades capitalistas, o discurso ideológico dirige de tal maneira a determinação de todos os valores que correntemente não temos a menor suspeita de que fomos induzidos a acolher, sem questionamento, um determinado conjunto de valores ao qual se poderia opor uma posição alternativa bem fundamentada, juntamente com seus comprometimentos mais ou menos implícitos.

De certo, podemos dizer que como função, a ideologia dominante cria para os sujeitos processos de identificação, seja negando o que está dado como certezas, com evidências aparentemente incontestáveis, seja regulando essas certezas, pondo-as em novos patamares e atribuindo novos valores.

Referências

AMARAL, Maria Virgínia Borges. O Discurso Trabalbo na sociedade Moderna. IX Colóquio internacional Marx Engels Centro de Estudos Marxistas (Cemarx), Unicamp 2018.

ANTUNES, Ricardo. Adeus ao trabalho? Ensaio sobre as metamorfoses e a centralidade do mundo do trabalbo. $8^{\text {a }}$ edição. 2002

ARANHA, Maria Lúcia de Arruda. e MARTINS, Maria Helena Pires. Filosofando: Introdução à filosofia. São Paulo: Moderna, v. 2, 1993. 
ARroYO, Miguel. A Educação de Jovens e Adultos em tempos de exclusão. Alfabetização e Cidadania. São Paulo: Rede de Apoio à Ação Alfabetizadora do Brasil (RAAAB), n.11, abril 2001.

CHAVES-GAMBOA, Márcia.; SÁNCHEZ GAMBOA, Silvio Áncizar. Teorias e pesquisas em educação: os pós-modernismos. Maceió: Edufal, 2011.

DE LA FARE, Mónica; CORRÊA, Guilherme Carlos. A EJA como analisador de práticas educacionais em contextos de expansão da escolaridade. Educação Por Escrito, 2015. DI

FREIRE, Paulo. A importância do ato de ler: em três artigos que se complementam. 23.ed. S P: Autores associados: Cortez, 1989.

FRIGOTTO, Gaudêncio. O enfoque da dialética materialista histórica na pesquisa educacional. In: Metodologia da pesquisa educacional (Fazenda, I. et al) pp. 71 90, São Paulo: Cortez, 1989.

GADOTTI, Moacir e BRANDÃO, José (orgs.). Educação de Jovens e Adultos: teoria, prática e proposta. 9. ed. São Paulo: Cortez: Instituto Paulo Freire, 2007.

GAULLIER Xavier, La deli-me carrière, Ed. Seuil: Paris, 1988.

KONDER, Leandro. A poesia de Brecht e a história. Rio de Janeiro: Jorge Zahar, 1996.

LBORNOZ, Suzana. O que é trabalho. $3^{\text {a }}$ Ed. São Paulo: Brasiliense, 1988.

LORENZATTI, María del Carmen. Contextos, Sujetos, Procesos en Escuelas de Jóvenes y Adultos. Topos \& Tropos,3,1-10.2005.

MAGALHÃES, Belmira. e SOBRINHO, Helson Flávio da Silva. Materialidades discursivas e o funcionamento da ideologia e do inconsciente na produção de sentidos. Revista Gragoatá. Niterói, n. 34, p. 95-111, 1. sem. (2013).

MARX, Karl. e ENGELS, Friedrich. A Ideologia Alemã. Obras Escolhidas. São Paulo: Edições Avante, 2006.

MAYA, Paulo Valério Ribeiro. Trabalho e tempo livre: uma abordagem crítica. In JACQUES, MGC., et al. org. Relações sociais e ética [online]. Rio de Janeiro: Centro Edelstein de Pesquisas Sociais, 2008. p. 31 - 47.

MÉSZÁROS, István. A educação para além do capital. São Paulo: Boitempo, v. 2, 2008. 
Estrutura social e formas de consciência II: a dialética da estrutura e da história. São Paulo: Boitempo, v. 2, 2011.

Para além do capital: rumo a uma teoria da transição - 1. ed. revista. SP: Boitempo, 2011.

NETTO, José Paulo. Introdução ao estudo do método de Marx. SP: Expressão Popular, 2011.

OLIVEIRA, Ana Cristina Oliveira de. Marx e o Marxismo: teoria e prática Universidade Federal Fluminense - Niterói - RJ -2011 - Anais.

ORLANDI, Eni Puccinelli. Análise de discurso. Princípios e procedimentos. SP, Pontes, 2012.

Pontes, 2012.

Discurso em Análise: Sujeito, Sentido, Ideologia. Campinas, SP,

ORLANDI, Eni Puccinelli. Interpretação, Vozes, Rio de Janeiro, 1996.

PÊCHEUX, Michel. e FUCHS, Catherine. (1997). A propósito da análise automática do discurso: atualização e perspectivas (1975). Em F. Gadet, \& T. Hak, (Orgs.). Por uma análise automática do discurso, uma introdução à obra de Michel Pêcheux. (B. S. Mariani [et al.], Trad.), (p. 163-246). Campinas, SP: Editora Unicamp.

PIERRO, Maria Clara. Educação de jovens e adultos na América Latina e Caribe: trajetória recente. Cedernos de Pesquisa, v. 38, n. 134, p. 367-391, 2013.

PUIGGRÓS, Adriana. Qué pasó en la educación argentina: Breve historia desde la conquista hasta el presente. Medicino ampliada. Editorial Galerna, 2016.

SÁNCHEZ GAMBOA, Silvio Áncizar. Pesquisa em Educação: métodos e epistemologias. 2a. ed. Chapecó SC: ARGOS, 2012.

Reações ao giro linguístico: o resgate da ontologia ou do real, independente da consciência e da linguagem. Porto Alegre, RS: CBCE, 2009.

SANCHEZ VASQUEZ, Adolfo. Filosofia da Práxis. Rio de Janeiro, Paz e Terra, 1986.

SAVIANI, Demerval. Politica educacional brasileira: limites e perspectivas. Revista de Educação PUC Campinas, Campinas, n.24, jun., p.7- 16, 2008. 
O trabalho como principio educativo frente às novas tecnologias. Novas tecnologias, trabalho e educação: um debate multidisciplinar. Petrópolis: Vozes, p. 147164, 1994.

SOUSA JUNIOR, Justino de. "Marx e a crítica da educação: da expansão liberaldemocrática à crise regressivo-destrutiva do capital." Aparecida, SP: Ideias \& Letras.2010.

TAFFAREL, Celi Nelza Zülke.; LACKS, Solange. e SANTOS JÚNIOR, Cláudio Lira. Teorias e práticas pedagógicas: realidade e possibilidade. In: SÁNCHEZ GAMBOA, S; CHAVES-GAMBOA, M. (Orgs.). Teorias e Pesquisas em Educação: os pós-modernismos. Maceió: EDUFAL, 2011.

VALDÉS, Raul et al (coord.). Contribuições conceituais da educação de pessoas jovens e adultas: rumo à construção de sentidos comuns na diversidade. Goiânia: Editora UFG, 2014.

Submetido em: $12 / 04 / 2020$

Aceito em: 09/06/2020

Publicado em: 02/07/2020 